\title{
Глубинный цикл углерода: система «әклогит-карбонатит-алмаз» в природной лаборатории «Тонсвика», Скандинавские Каледониды
}

\section{Зозуля Д.Р.}

Геологический институт КНЦ РАН, Anamumbl,zozulya@geoksc.apatity.ru

Аннотация. В статье приведены данные о новом генетическом типе карбонатитов, формирующегося в условиях ультравысокого давления при парциальном плавлении карбонатизированных эклогитов. Показано, что при понижении температуры во вмещающих породах и за счет привноса летучих (главным образом $\mathrm{H}_{2} \mathrm{O}$, $\left.\mathrm{CH}_{4}, \mathrm{~F}\right)$ происходит понижение фугитивности кислорода и образуются алмазы. Полученные результаты могут быть использованы в изучении глобального цикла углерода.

Ключевые слова: эклогит; карбонатит; алмаз; углерод; субдукция.

\section{Deep carbon cycle: «eclogite-carbonatite-diamond» system in the natural laboratory «Tonsvik», Scandinavian Caledonides}

\author{
Zozulya D. \\ Geological Institute, Kola Science Centre RAS, Apatity, zozulya@geoksc.apatity.ru
}

\begin{abstract}
The article presents data on a new genetic type of carbonatites, which is being formed under the conditions of ultrahigh pressure with the partial melting of carbonatized eclogites. It is shown that with a decrease in temperature in the host rocks and due to the influx of volatiles (mainly $\mathrm{H}_{2} \mathrm{O}, \mathrm{CH}_{4}, \mathrm{~F}$ ), oxygen fugacity decreases and diamonds are formed. The results can be used to study the global carbon cycle.
\end{abstract}

Key words: eclogite; carbonatite; diamond; carbon; subduction.

Генезис карбонатитовых расплавов путем парциального плавления мантийных пород (перидотитов и эклогитов) является одним из наиболее распространенных предположений способа происхождения карбонатитов. Существует значительное количество экспериментальных исследований и численных моделей, подтверждающих этот способ происхождения карбонатитов (Dasgupta et al., 2004; Yaxley, Brey, 2004; Kiseeva et al., 2012; и др.). Карбонатизация и метасоматоз сублитосферной мантии также рассматриваются как одни из важных механизмов формирования алмазоносных кимберлитов и лампроитов; известны и единичные проявления алмазоносных карбонатитов. Наконец, существуют многочисленные находки алмазоносных эклогитов как в пределах орогенных поясов, так и в виде мантийных ксенолитов из трубок взрыва и даек ультраосновных пород. Все вышесказанное позволяет предположить генетическую связь между эклогитами, карбонатитами и алмазоносными породами. Проявление Тонсвика в Северной Норвегии (район г.Тромсе) является единственным известным на сегодня природным объектом (лабораторией), где выявлены все компоненты системы «эклогит-карбонатит-алмаз» и возможны исследования глубинного сегмента глобального цикла углерода in situ.

Проявление карбонатитов Тонсвика (рис. 1) обнаружено в пределах Скандинавских каледонид и представляет серию жил и даек во вмещающем комплексе эклогитов и его ретроградных продуктов (карбонатизированные и метасоматизированные эклогиты), гранатовых клинопироксенитов и глиммеритов, а также гранат-фенгитовых гнейсов и мраморов (Ravna et al., 2017). Во вмещающих породах (гранат-кианит-фенгитовые гнейсы) обнаружены алмазы (Janak et al., 2013). Карбо-

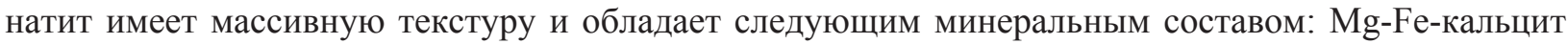

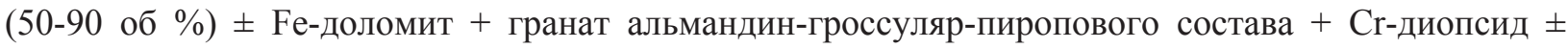
омфацит + флогопит; второстепенные и акцессорные минералы: апатит, рутил, ильменит, алланит, титанит, циркон, монацит. Реже встречаются жилы (до 10 см мощности) практически мономинеральных карбонатных пород. Во всех случаях силикокарбонатиты и карбонатиты имеют резкие интрузивные контакты с вмещающими породами, при этом наблюдается интенсивная фенитизация последних К-содержащими флюидами с образованием флогопита на контакте. 


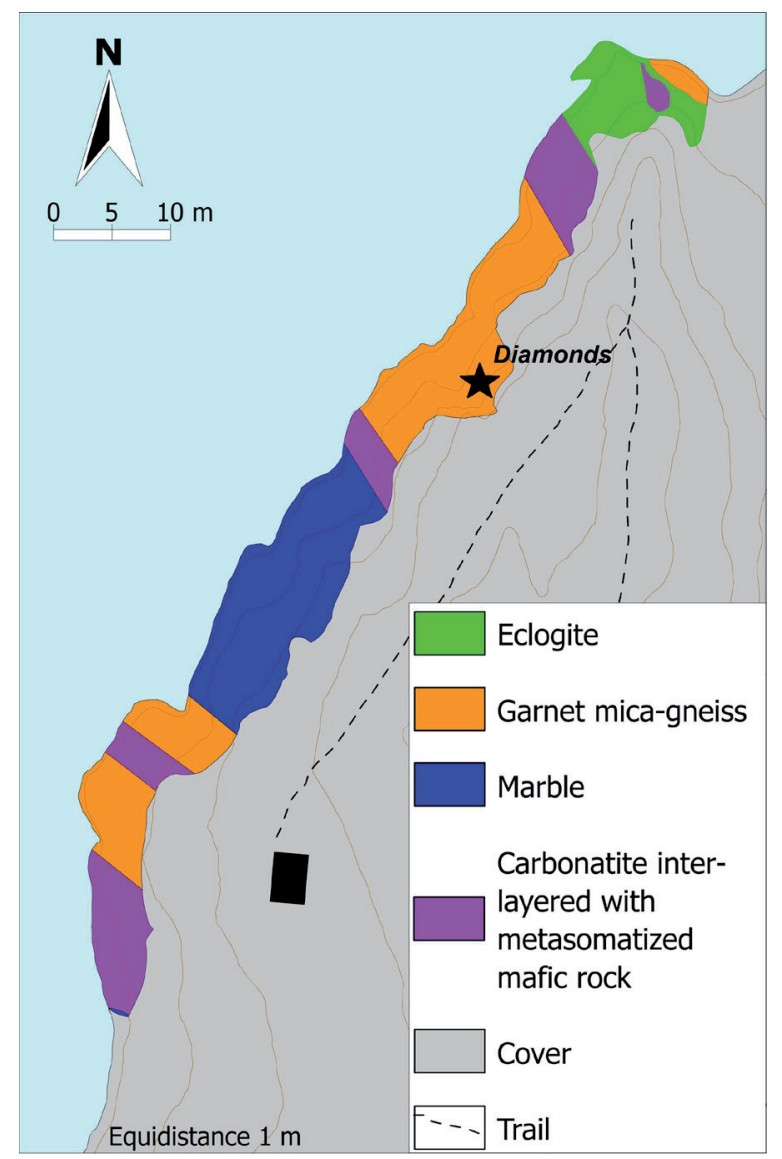

Рис. 1. Геологическая схема строения проявления Тонсвика.

Fig. 1. Geological scheme of the Tonsvik occurrence structure.
$\mathrm{U}-\mathrm{Pb}$ возрасты циркона и титанита из карбонатита составляют 452-455 млн. лет (Ravna et al., 2017) и совпадают в пределах ошибки с возрастом вмещающих эклогитов $((452.1 \pm 1.7)$ млн. лет). Хондрит-нормализованные распределения несовместимых элементов и REE сходны с таковыми для типичных карбонатитов и отличаются от ассоциирующих мраморов значительно более высокими содержаниями (Ravna et al., 2017).

Содержание и соотношения некоторых редких и рассеянных элементов являются весьма информативными для определения тектонической обстановки формирования карбонатитовых комплексов. Подавляющее большинство карбонатитов Мира образуется во внутриплитной обстановке, в частности в континентальных рифтах. Эти карбонатиты характеризуются высокими содержаниями LIL (особенно, Sr и Ba) и HFS элементов (средние значения для $\mathrm{Zr}, \mathrm{Nb}, \mathrm{Hf}$, Та составляют, соответственно, 256.4, 308.9, 4.3, 8.9 ppm (Chakhmouradian, 2006)). Карбонатиты, образующиеся в субдуционной и коллизионной обстановках обладают высокими содержанями LIL и значительно меньшими - HFS элементов. Так, для комплекса Эден Лэйк приводятся следующие данные (Chakhmouradian et al., 2008): 47-98 pрт для Zr, 4.0 для $\mathrm{Nb}, 1.5-2.4$ для $\mathrm{Hf}$, и 0.2 для Та. Для карбонатита Тонсвика нами получены следующие содержания HFSE (Zr варьирует от 26 до 460 ppm (среднее значение 114 ppm); Nb: 1-31 ppm (18 ppm); Hf: 0-7.7 ppm (2.5 ppm); Тa: 0.5-2.0 ppm (1.2 ppm)). В связи с тем, что содержания HFSE в карбонатитах имеют значительные вариации, для установления исходных характеристик были использованы отношения «канонических» элементов $\mathrm{Zr} / \mathrm{Nb}$, $\mathrm{Zr} / \mathrm{Hf}, \mathrm{Nb} / \mathrm{Ta}$. Средний карбонатит (внутриплитный) имеет следующие средние значения $\mathrm{Zr} / \mathrm{Nb}=0.8, \mathrm{Zr} / \mathrm{Hf}=60, \mathrm{Nb} / \mathrm{Ta}=35$ (Chakhmouradian, 2006). Для карбонатита Тонсвика эти значения $(\mathrm{Zr} / \mathrm{Nb}=18, \mathrm{Zr} / \mathrm{Hf}=42$ and $\mathrm{Nb} / \mathrm{Ta}=18)$ значительно отличаются, но при этом сходны с таковыми

Pис. 2. $\mathrm{Nb} / \mathrm{Ta}$ vs. $\mathrm{Zr} / \mathrm{Nb}$ диаграмма для карбонатитов Тонсвика, среднего внутриплитного карбонатита и карбонатитов в коллизионных и субдукционных обстановках (Эден Лэйк (Chakhmouradian et al., 2008), Италия (Stoppa, Wooley, 1997; D’Orazio et al., 2007), Сев. Китай (Xu et al., 2010), Антарктика (Hagen-Peter, Cottle, 2016), СВ Китай (Ying et al., 2004), Ю3 Китай (Hou et al., 2006)).

Fig. 2. $\mathrm{Nb} / \mathrm{Ta}$ vs. $\mathrm{Zr} / \mathrm{Nb}$ diagram for carbonatites in Tonsvik, average intraplate carbonatites in collisional and subduction settings (Eden Lake (Chakhmouradian et al., 2008), Italy (Stoppa, Wooley, 1997; D’Orazio et al., 2007), North. China (Xu et al., 2010), Antarctic (Hagen-Peter, Cottle, 2016), NE China (Ying et al., 2004), SW China (Hou et al., 2006)).

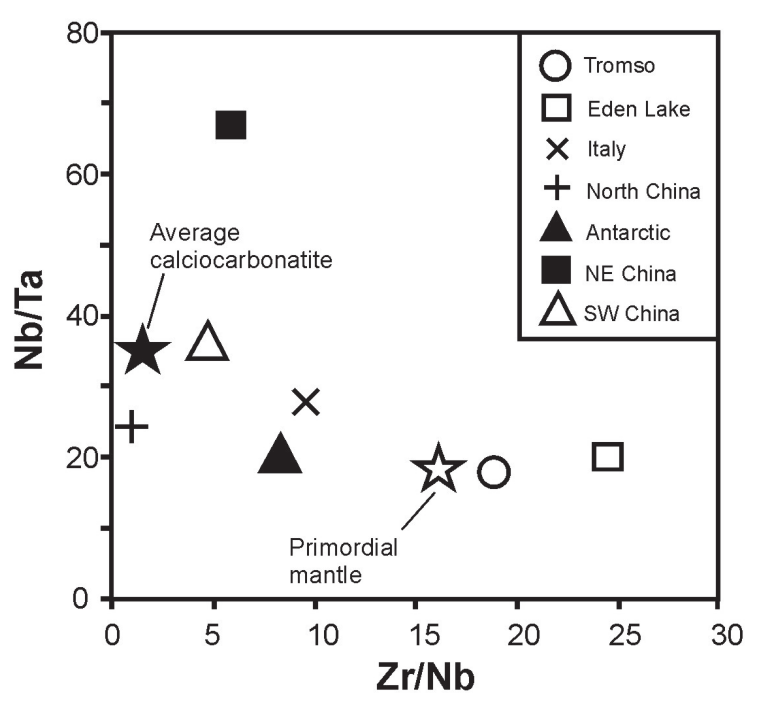


для карбонатитов субдукционных и коллизионных обстановок (рис. 2). Анализ распределения указанных отношений может так же иметь петрогенетическое значение. Карбонатиты Тонсвика имеют отношения $\mathrm{Zr} / \mathrm{Nb}, \mathrm{Nb} / \mathrm{Ta}$, близкие к примитивной мантии. В совокупности с низкими HFSE это указывает на то, что мантийный источник в нашем случае не был метасоматизирован перед плавлением, что характерно для внутриплитных карбонатитов. Таким образом, можно предполагать, что карбонатитовый расплав Тонсвика образовался путем прямого парциального плавления либо мантийных лерцолитов («магнезиальные» карбонатные расплавы), либо эклогитов («кальциевые» карбонатные расплавы). Минеральный состав карбонатитов Тонсвика (см. выше) свидетельствует об «эклогитовом» субстрате.

Проведенные $\mathrm{Sr}-\mathrm{Nd}$ изотопные исследования для пород проявления Тонсвика показали следующие результаты: для силикокарбонатитов получены значения $0.705-0.708$ для ${ }^{87} \mathrm{Sr} /{ }^{86} \mathrm{Sr}$ и -1 to -2 для $\varepsilon_{\mathrm{Nd}}$, при этом они сходны с таковыми для мраморов; карбонатит имеет сходные значения начальных отношений изотопов $\mathrm{Sr}$, но более негативные (-3.3) значения $\varepsilon_{\mathrm{Nd}}$; эклогит имеет наиболее радиогенные отношения $\operatorname{Sr}(0.708-0.710)$ и нерадиогенные - $\mathrm{Nd}(-2.4$ to -3.3$)$; карбонатизированный и метасоматизированнй эклогиты имеют сходные с карбонатитами начальные отношения стронция, но диаметрально различные $\varepsilon_{\mathrm{Nd}}$ (нерадиогенные и радиогенные значения, соответственно). Сходные изначальные стронциевые отношения для карбонатита и изменененных эклогитов могут говорить об их генетиеской связи. Сравнение начальных изотопных отношений $\mathrm{Sr}$ и $\mathrm{Nd}$ карбонатитов Тонсвика с карбонатитами из разных тектонических обстановок показывает, что исследуемые карбонатиты по своим характеристикам сходны с карбонатитами из коллизионных и субдукционных обстановок (рис. 3).

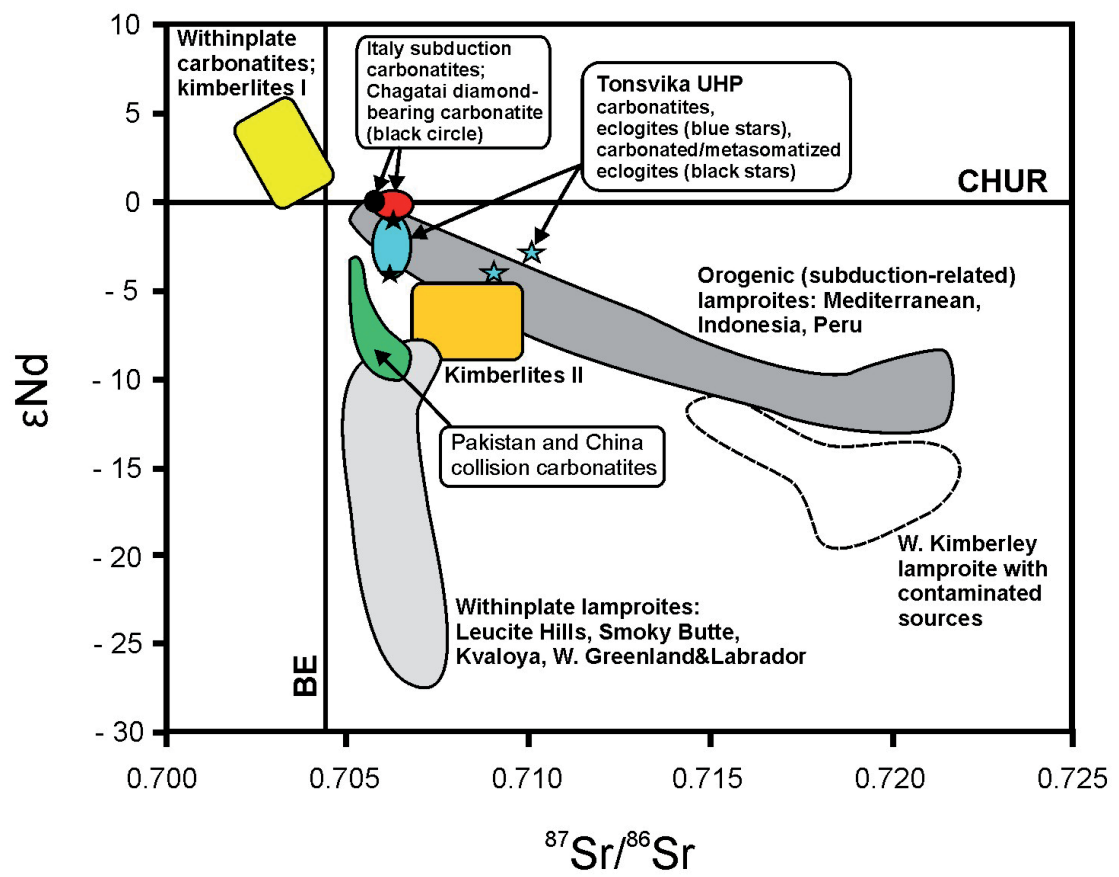

Рис. 3. Диаграмма $\varepsilon \mathrm{Nd}(\mathrm{t}) \mathrm{vs}\left({ }^{87} \mathrm{Sr} r{ }^{86} \mathrm{Sr}\right){ }_{i}$ для карбонатитов, мрамора и эклогитов проявления Тонсвика в сравнении с опубликованными данными для внутриплитных карбонатитов, кимберлитов 1 и 2 , внутриплитных и орогенных лампроитов Мира, а так же для карбонатитов из субдукционных и коллизионных обстановок (Италия (D’Orazio et al., 2007; Rosatelli et al., 2007), Пакистан (Tilton et al., 1998), Китай (Гималаи) (Hou et al., 2006), алмазоносные карбонатиты Чагатай (Тянь-Шань) (Lapin et al., 2002; Moore et al., 2009)).

Fig. 3. Diagram $\varepsilon N d(t)$ vs $(87 \mathrm{Sr} / 86 \mathrm{Sr}) \mathrm{i}$ for carbonatites, marble and eclogites of the Tonsvik occurrence compared to data on intraplate carbonatites, kymberlites 1 and 2, intraplate and orogenic lamproites in the world, as well as on carbonatites from subduction and collisional settings (Italy (D'Orazio et al., 2007; Rosatelli et al., 2007), Pakistan (Tilton et al., 1998), China (Himalayas) (Hou et al., 2006), diamond-bearing carbonatites of the Chagatay complex (Tien Shan) (Lapin et al., 2002; Moore et al., 2009)). 
Расчеты Р-Т параметров (рис. 4) показали, что карбонатиты формировались при давлении 3.23.6 GPa и температуре $970-1100^{\circ} \mathrm{C}$. При этом, данные экспериментов по плавлению безводного карбонатизированного эклогита (Dasgupta et al., 2004; Yaxley \& Brey, 2004; Kiseeva et al., 2012) показывают, что солидус карбонатита может варьировать в значительном диапазоне температур и давления (1000-1300 두 4 -5 GPa). Все эти параметры превышают значения «горячего» субдуцированного слэба. Однако, значительное понижение температуры плавления эклогита с образованием карбонатитового расплава может быть достигнуто путем добавления в систему $\mathrm{Na}_{2} \mathrm{O}, \mathrm{H}_{2} \mathrm{O}$ и $\mathrm{F}$, что показано экспериментальными данными (Yaxley, Brey, 2004; Kiseeva et al., 2012; Jago, Gittins, 1991).

Поскольку карбонатиты Тонсвика содержат значительное количество флогопита и фторапатита, можно предположить, что присутствие $\mathrm{F}, \mathrm{P}_{2} \mathrm{O}_{5}, \mathrm{~K}_{2} \mathrm{O}$ и $\mathrm{H}_{2} \mathrm{O}$ могло сыграть существенную роль в понижении солидуса пород источника (карбонатизированный эклогит) вплоть до температур субдуцировааного слэба. Другим важным источником воды может быть реакция $\mathrm{CH}_{4}$-содержащего флюида из глубинных горизонтов мантии с кислородом из субдуцированного слэба:

$$
\mathrm{CH}_{4}+\mathrm{O}_{2} \rightarrow 2 \mathrm{H}_{2} \mathrm{O}+\mathrm{C}
$$

как было предложено в работе (Foley, 2011). Данная реакция может быть использована для объяснения происхождения алмазов в проявлении Тонсвика. Алмаз-содержащие кианит-фенгитовые гнейсы формировались в условиях 3.2-3.6 GРа и значительно меньших температурах - около $750-800^{\circ} \mathrm{C}$ (рис. 4). Наряду с возможным очевидным понижением температуры в системе, для формирования алмаза необходимо наличие восстановленного углерода. Кроме, внешнего (глубинного) источника углерода, другим его важным источником могут быть карбонаты самого месторождения. Экспериментальными и натурными исследованиями (Tao et al., 2018) показано, что образование графита и легких углеводородов в карбонатизированных эклогитах может происходить путем восстановления карбоната за счет низкой фугитивности кислорода ( FMQ $-2.5 \log )$. При этом главным условием прохождения окислительно-восстановительной реакции является присутствие Fе компонента в карбонате и в общем виде реакция может быть представлена в виде:

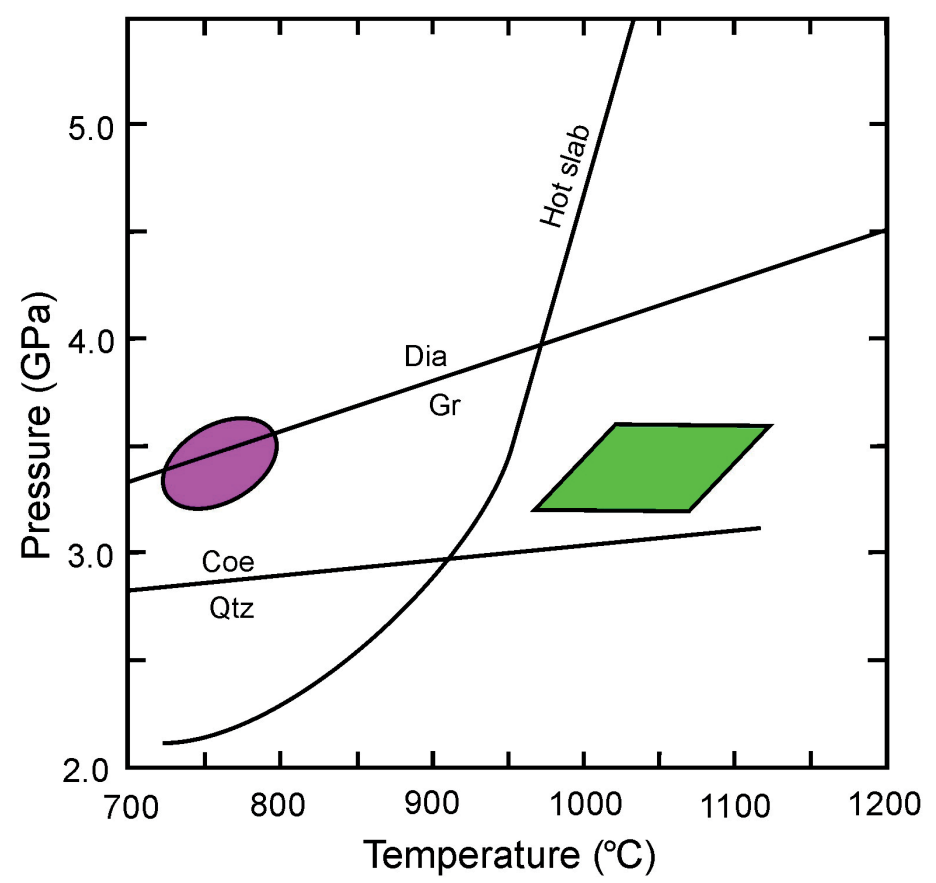

Рис. 4. Р-Т диаграмма для карбонатитов (зеленый параллелограмм) и алмаз-содержащих пород (красный овал) проявления Тонсвика. Траектория слэба по (van Keken et al., 2002).

Fig. 4. P-T diagram for carbonatites (green parallelogram) and diamond-bearing rocks (red oval) of the Tonsvik occurrence. Trajectory of the slab according to (van Keken et al., 2002). 


$$
3 \mathrm{FeCO}_{3}+\mathrm{H}_{2} \mathrm{O} \rightarrow \mathrm{Fe}_{3} \mathrm{O}_{4}+3 \mathrm{CO}_{2}+\mathrm{H}_{2}
$$

Следует отметить, что в проявлении Тонсвика карбонаты имеют составы $\mathrm{Mg}$-Fe-кальцита и Fe-доломита, а магнетит является характерным акцессорным минералом. Взаимоотношения других $\mathrm{Fe}-\mathrm{Ti}$ оксидов, рутила и ильменита, также могут свидетельствовать об относительном уменьшении фугитивности кислорода на поздних стадиях кристаллизации карбонатитового расплава. Характерной особенностью Fe-Ті оксидов в карбонатите Тонсвика является более поздняя кристаллизация ильменита по отношению к рутилу, при этом ильменит образует реакционные каймы по рутилу. Данная реакция идет с поглощением кислорода:

$$
2 \mathrm{Fe}+2 \mathrm{TiO}_{2}+\mathrm{O}_{2} \rightarrow 2 \mathrm{FeTiO}_{3}
$$

Более того, образование ильменита по рутилу может идти и с разложением воды и выделением водорода в систему:

$$
\mathrm{Fe}+\mathrm{TiO}_{2}+\mathrm{H}_{2} \mathrm{O} \rightarrow \mathrm{FeTiO}_{3}+\mathrm{H}_{2}
$$

Таким образом, на поздних этапах кристаллизации карбонатита в проявлении Тонсвика происходило смещение в сторону восстановительных условияй, что при наличии необходимых Р-Т параметров могло привести к кристаллизации алмаза.

Сходные изотопные отношения $\mathrm{Nd}$ и $\mathrm{Sr}$ в эклогитах, карбонатитах и лампроитах (в том числе, алмазоносных) из субдукционных обстановок (см. рис. 3) так же указывают на их парагенетическую связь и интегрированную роль в глубинном цикле углерода. При этом, основными различиями для систем «карбонатит-алмаз» и «лампроит-алмаз» могут быть: (а) разный состав метасоматизирующих флюидов (карбонатные и водные, соответственно); (б) разная степень метасоматической переработки и парциального плавления субстрата; (в) разные Р-Т условия формирования магм.

Работа выполнена в рамках темы НИР № 0226-2019-0053.

\section{Литература}

1. Chakhmouradian A.R. High-field-strength elements in carbonatitic rocks: Geochemistry, crystal chemistry and significance for constraining the sources of carbonatites // Chemical Geology. 2006. V. 235(12). P. 138-160.

2. Chakhmouradian A.R., Mumin A.H., Demény A., Elliott B. Postorogenic carbonatites at Eden Lake, TransHudson Orogen (northern Manitoba, Canada): Geological setting, mineralogy and geochemistry // Lithos. 2008. V. 103(3-4). P. 503-526.

3. Dasgupta R., Hirschmann M.M., Withers A.C. Deep global cycling of carbon constrained by the solidus of anhydrous carbonated eclogite under upper mantle conditions // Earth and Planetary Science Letters. 2004. V. 227. P. 73-85.

4. D’Orazio M., Innocenti F., Tonarini S., Doglioni C. Carbonatites in a subduction system: The Pleistocene alvikites from Mt. Vulture (southern Italy) // Lithos. 2007. V. 98. P. 313-334.

5. Foley S. A reappraisal of redox melting in the Earth's mantle as a function of tectonic setting and time // Journal of Petrology. 2011. V. 52. P. 1363-1391.

6. Hagen-Peter G., Cottle J.M. Synchronous alkaline and subalkaline magmatism during the late Neoproterozoicearly Paleozoic Ross orogeny, Antarctica: Insights into magmatic sources and processes within a continental arc // Lithos. 2016. V. 262. P. 677-698.

7. Hou Z., Tian S., Yuan Z., Xie Y., Yin S., Yi L., Fei H., Yang Z. The Himalayan collision zone carbonatites in western Sichuan, SW China: Petrogenesis, mantle source and tectonic implication // Earth and planetary Science Letters. 2006. V. 244. P. 234-250.

8. Jago B.C., Gittins J. The role of fluorine in carbonatite magma evolution // Nature 1991. V. 349. P. 56-58.

9. Janák M., Ravna E.J.K., Kullerud K., Yoshida K., Milovsky R., Hirajima T. Discovery of diamond in the Tromsø Nappe, Scandinavian Caledonides (N. Norway) // Journal of Metamorphic Geology. 2013. V. 31. P. 691-703.

10. Kiseeva E.S., Yaxley G.M., Hermann J., Litasov K.D., Rosenthal A., Kamenetsky V.S. An experimental study of carbonated eclogite at 3.5-5.5 GPa-Implications for silicate and carbonate metasomatism in the cratonic mantle // Journal of Petrology. 2012. V. 53. P. 727-759.

11. Lapin A.V., Divaev F.K., Kostityn Yu.A. Petrochemical interpretation of carbonatite-like rocks from the Chagatai Complex of the Tien Shan with application to the problem of diamond potential // Petrology. 2005. V. 13(5). P. 499-511. 
12. Moore K.R., Wall F., Divaev F.K., Savatenkov V.M. Mingling of carbonate and silicate magmas under turbulent flow conditions: Evidence from rock textures and mineral chemistry in sub-volcanic carbonatite dykes, Chagatai, Uzbekistan // Lithos. 2009. V. 110. P. 65-82.

13. Ravna E.K., Zozulya D., Kullerud K., Corfu F., Nabelek P.I., Janak M., Slagstad T., Davidsen B., Selbekk R.S., Schertl H.-P. Deep-seated carbonatite intrusion and metasomatism in the UHP Tromsø nappe, Northern Scandinavian Caledonides - A natural example of generation of carbonatite from carbonated eclogite. Journal of Petrology, 2017. V. 58(12). P. 2403-2428.

14. Rosatelli G., Wall F., Stoppa F. Calcio-carbonatite melts and metasomatism in the mantle beneath Mt. Vulture (Southern Italy) // Lithos. 2007. V. 99. P. 229-248.

15. Stoppa F., Woolley A.R. The Italian carbonatites: Field occurrence, petrology and regional significance // Mineralogy and Petrology. 1997. V. 59. P. 43-67.

16. Tao R., Zhang L., Tian M., Zhu J., Liu X., Liu J., Höfer H.E., Stagno V., Fei Y. Formation of abiotic hydrocarbon from reduction of carbonate in subduction zones: Constraints from petrological observation and experimental simulation // Geochimica et Cosmochimica Acta. 2018. V. 239. P. 390-408.

17. Tilton G.R., Bryge J.G., Mateen A. Pb-Sr-Nd isotope data from 30 and 300 Ma collision zone carbonatites in Northwest Pakistan // Journal of Petrology. 1998. V. 39. P. 1865-1874.

18. van Keken P.E., Kiefer B., Peacock S.M. High resolution models of subduction zones: implications for mineral dehydration reactions and the transport of water into the deep mantle // Geochemistry, Geophysics, Geosystems. 2002. 3. doi:10.1029/2001GC000256.

19. Xu C., Kynicky J., Chakhmouradian A.R., Qi L., Song W. A unique Mo deposit associated with carbonatites in the Qinling orogenic belt, central China // Lithos. 2010. V. 118. P. 50-60.

20. Yaxley G.M., Brey G.P. Phase relations of carbonate-bearing eclogite assemblages from 2.5 to 5.5 GPa: implications for petrogenesis of carbonatites // Contributions to Mineralogy and Petrology. 2004. 146. P. 606-619.

21. Ying J., Zhou X., Zhang H. Geochemical and isotopic investigation of the Laiwu-Zibo carbonatites from western Shandong Province, China, and implications for their petrogenesis and enriched mantle source // Lithos. 2004. V. 75. P. 413-426. 